\title{
THE FATIGUE LIFE OF CABLES IN AIRCRAFT FLIGHT CONTROL SYSTEMS
}

\author{
Mariusz Kubryn ${ }^{1}$, Henryk Gruszecki ${ }^{1}$, Leszek Pieróg ${ }^{1}$, Jerzy Chodur ${ }^{1}$, \\ Janusz Pietruszka1, Józef Brzęczek² \\ ${ }^{1}$ Polskie Zakłady Lotnicze Sp. z o.o., Mielec, Poland \\ ${ }^{2}$ Politechnika Rzeszowska, Rzeszów, Poland \\ janusz.pietruszka@lmco.com
}

\begin{abstract}
The cable flight control systems are commonly used for the control of small airplanes. In these systems, the cables are the only elements transmitting loads from the pilot to the control surfaces. During a flight the cables are moving through pulleys and are subjected to variable loads. A simple analysis of stress in the cable shows that the stress generated by the cyclical bending on the pulleys causes the fatigue of the wires.

This phenomenon was noticed on a military aircraft of the M28 family during periodic maintenance inspection in 2007. The endurance tests of KSAN cables of the diameter equal to $3.5 \mathrm{~mm}$ and $1.8 \mathrm{~mm}$ were performed at the PZL MIELEC. The tests showed the limited fatigue life of the cables due to a progressive increase in the number of broken wires.
\end{abstract}

Keywords: fatigue, cable flight control systems, cable endurance tests

\section{INTRODUCTION}

Aviation cables for flight control systems are made from carbon steel wires or stainless steel wires. Wires are of small diameter and high tensile strength. For example, cables made from zinc coated carbon steel according to the Russian standard TU 14-4-1266-83 [1], are used in the PZL M28 aircraft. Fig. 1 shows the cross-section of cable KSAN 3,5 with nominal diameter of $3.5 \mathrm{~mm}$. The cable is made from 7 strands. Each strand contains 19 wires of diameter $0.22 \div 0.30 \mathrm{~mm}$ (in total: 133 wires) of minimum tensile strength $2160 \mathrm{MPa}$. The nominal wires cross section is 5.447 sq.mm, and minimum breaking force is $8600 \mathrm{~N}$. 


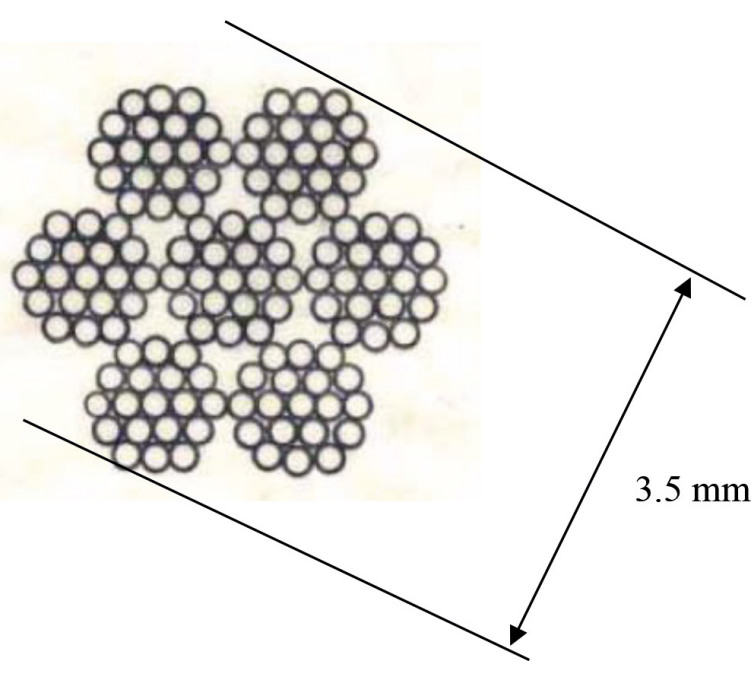

Fig. 1. Cross section of aviation cable KSAN 3,5 according to standard TU 14-4-1266-83

According to the standard TU 14-4-1266-83, the positive result of endurance test of the KSAN 3,5 cable is when breaking force after the test is at least $65 \%$ of the nominal force and the number of broken wires is not greater than $14 \%$ of 133 wires (18 wires).

In the year 2007, maintenance inspection of PZL M28 family airplanes operated by the Polish Air Force revealed an increased number of broken wires in the KSAN 3,5 cables in the elevator and rudder control systems - see Fig. 2. In some cases, the number of broken wires was greater than 8 , which is maximum allowable number.

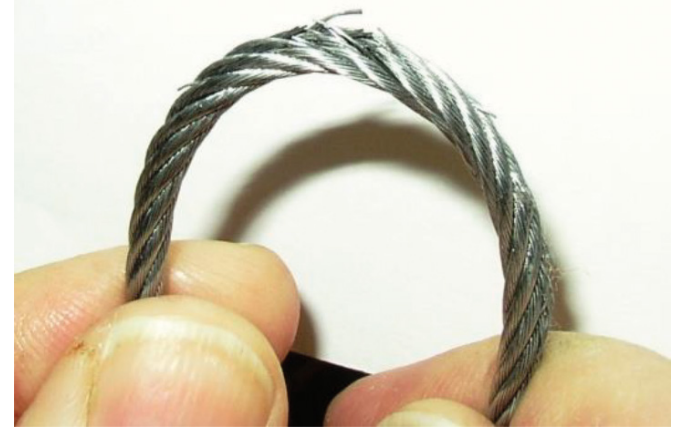

Fig. 2. The damaged cable KSAN 3,5 removed from the aircraft 
In response to this occurrence, the actions were undertaken by PZL MIELEC as the aircraft producer:

- checking of chemical composition and tensile strength of damaged cables,

- identifying the supplier of these cables,

- inspecting cables in control systems in other M28 airplanes,

- performing endurance tests of the KSAN 3,5 cables.

The chemical composition of the cable wires investigated was typical of carbon steel of grades 80,85 and 65 (Russian), i.e. with $0.8 \%, 0.85 \%$ and $0.65 \%$ of carbon respectively, typical of the KSAN 3,5 cables. Also, the breaking force during the tests was above the minimum - see Table 1 [2].

\begin{tabular}{|l|c|c|c|c|}
\hline & \multicolumn{3}{|c|}{ Chemical compound } & Breaking force \\
\hline & C & Mn & Si & N \\
\hline \multirow{2}{*}{ Specimen \#1 } & $0.85 \%$ & $0.48 \%$ & $0.24 \%$ & $\begin{array}{l}9.8 \mathrm{kN} \\
9.7 \mathrm{kN}\end{array}$ \\
\hline \multirow{2}{*}{ Specimen \#2 } & - & - & - & $9.4 \mathrm{kN}$ \\
& & & $0.4 \mathrm{kN}$ \\
\hline \multirow{2}{*}{ Specimen \#3 } & \multirow{2}{*}{$0.80 \%$} & $0.50 \%$ & $0.32 \%$ & $9.2 \mathrm{kN}$ \\
& & & & $9.0 \mathrm{kN}$ \\
Specimen \#4 & \multirow{2}{*}{$0.64 \%$} & $0.62 \%$ & $0.20 \%$ & $9.2 \mathrm{kN}$ \\
& & & & $9.7 \mathrm{kN}$ \\
& & &
\end{tabular}

Table 1. Chemical compound and breaking force of investigated KSAN 3,5 cable specimens

\section{ENDURANCE TESTS}

Extensive endurance tests of the KSAN 3,5 cable specimens were performed in the PZL MIELEC test laboratory. Simple stress analysis of the aircraft control system cables showed that cyclic bending of the rope on the pulleys was the main contributor to wires fatigue damage. The tests were performed both under the conditions as in the standard, and under the conditions more closely reflecting those in the PZL M28 aircraft. The test rig allowed the implementation of test sheaves of different diameters and different tension loads - see Fig. 3. 


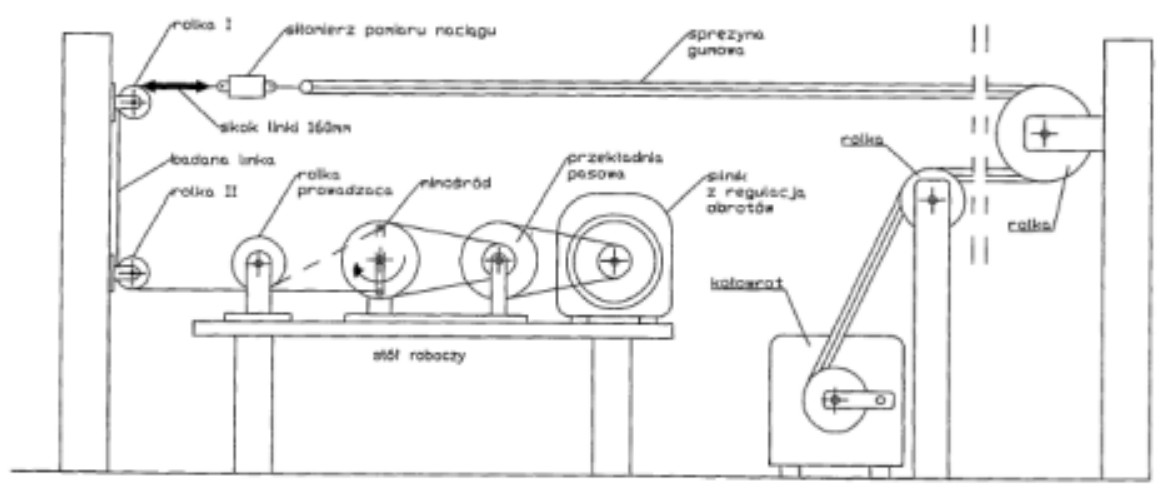

Fig. 3. Scheme of the test rig for cable specimens endurance tests. "Upper" and "lower "sheaves are visible as attached to the wall at left (see "rolka I" and "rolka II" on figure, respectively). The cable was put in motion through the eccentricity. Rubber hose (see "sprężyna gumowa" on figure) was used to maintain constant tension. Usually, the cable specimen length allowed test to be performed on both sheaves

\subsection{Endurance tests performed under the conditions as in the standard}

Endurance tests under the conditions as in the standard TU14-4-1266-83 (test sheave diameter $35 \mathrm{~mm}$, tension load $88 \mathrm{~N}$ ) were performed on one cable [2]. The cable was bent by 90 degrees on two sheaves of the same diameter, referred to as "upper" and "lower" following the test rig arrangement, so two results of the test were obtained. Number of reverses according to the standard is 70000 , but test was conducted up to 100000 reverses - see Fig. 4 below. Number of broken wires was observed after $20000,40000,50000,60000,70000,80000,90000$ and 100000 reverses. "L9 ns1" refers to the "upper" sheave, while "L9 ns2" refers to the "lower" sheave.

As presented in Fig. 4, the test result was positive, as at 70000 performed reverses number of broken wires at the "upper" sheave was 4, while on the "lower" sheave was 1. Breaking force after 70000 reverses was not measured as it would prevent further test conduction. A small number of broken wires after 70000 reverses indicated the fulfillment of the breaking forces condition.

This test also showed a significant increase in the number of broken wires after 70000 reverses, and significant scatter of the result between the "upper" and "lower" sheaves. 


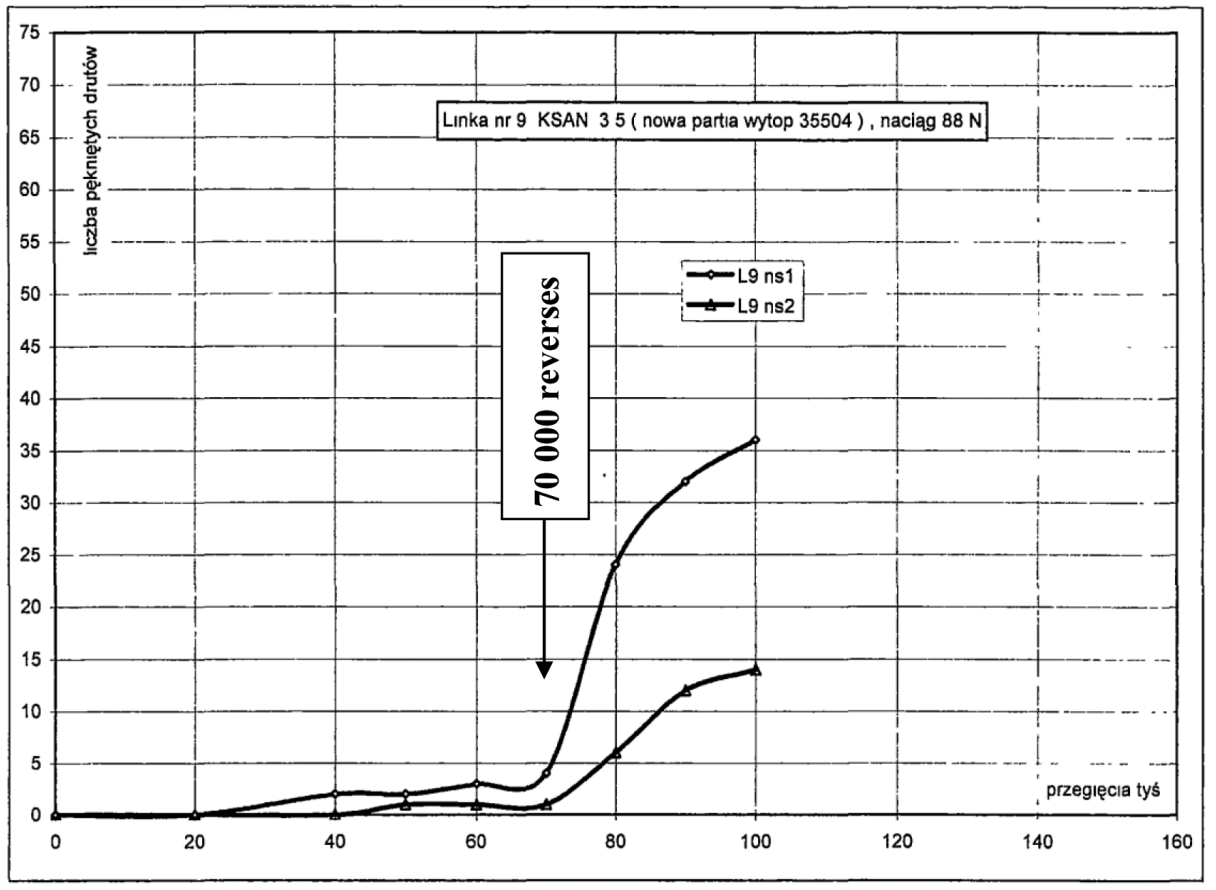

Fig. 4. Test result of the KSAN 3,5 cable specimen number L9 ("Linka $\mathrm{nr} 9$ KSAN 3,5...") endurance test performed according to the standard TU14-4-1266-83.

Number of thousands of reverses is on horizontal axis, while number of broken wires is on vertical axis. Test was conducted up to 100000 reverses. Results refer to "upper" and "lower" sheave

\subsection{Endurance tests performed under the PZL M28 conditions}

Endurance tests under the conditions reflecting those on the PZL M28 aircraft were performed with test sheaves diameter $64 \mathrm{~mm}$ [2]. Tension load was $392 \mathrm{~N}$ (nominal tension in the cable control system of PZL M28 in RT) or $707 \mathrm{~N}$ (tension measured in the cable control systems of some PZL M28 family airplanes). In total, 8 cable specimens were tested. In some cases, the cable was lubricated with grease for research purposes only (it is not allowed to be done by cable manufacturers). In each case the test was conducted until a significant number of broken wires, but in one case up to 1320000 reverses number of broken wires rose to 4 only - see Fig. 5 below. Typical tests results are shown in Fig. 6 (for cable tension load 392 N) and Fig. 7 (for cable tension load 707 N). 


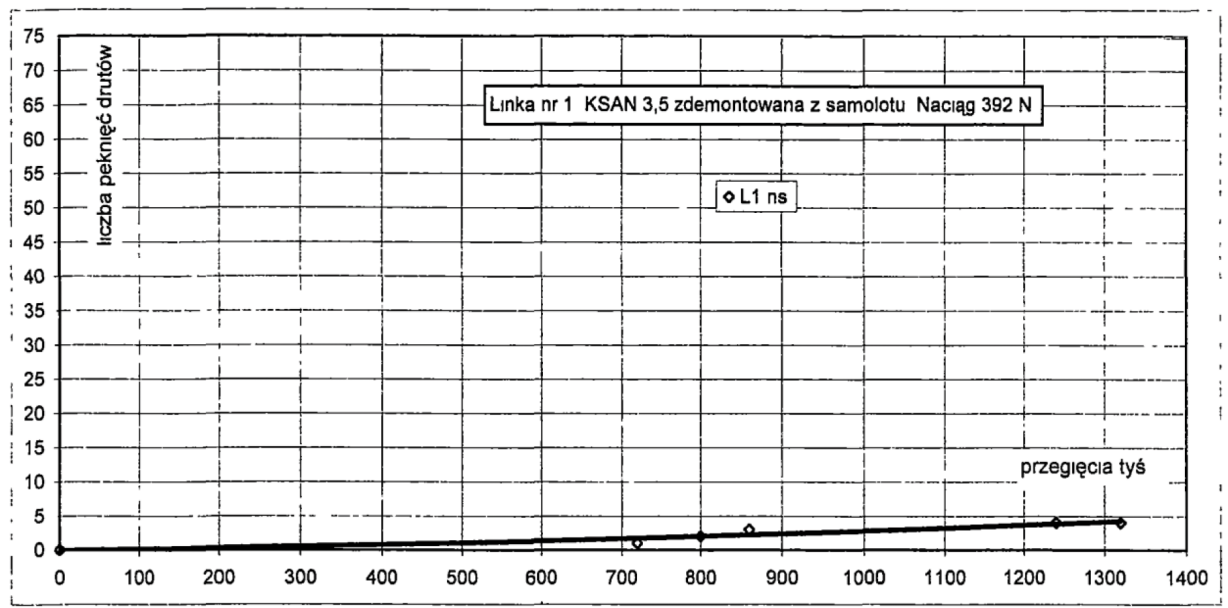

Fig. 5. Test result of the KSAN 3,5 cable specimen number L1 (“Linka $\mathrm{nr} 1 \mathrm{KSAN}$ 3,5 ...”) endurance test performed for sheaves diameter $64 \mathrm{~mm}$ and tension load $392 \mathrm{~N}$. Number of thousands of reverses is on horizontal axis, while number of broken wires is on vertical axis. Small length of this specimen caused that cable was bent only on one sheave. Test was conducted up to 1320000 reverses. Number of broken wires at the end of test was 4

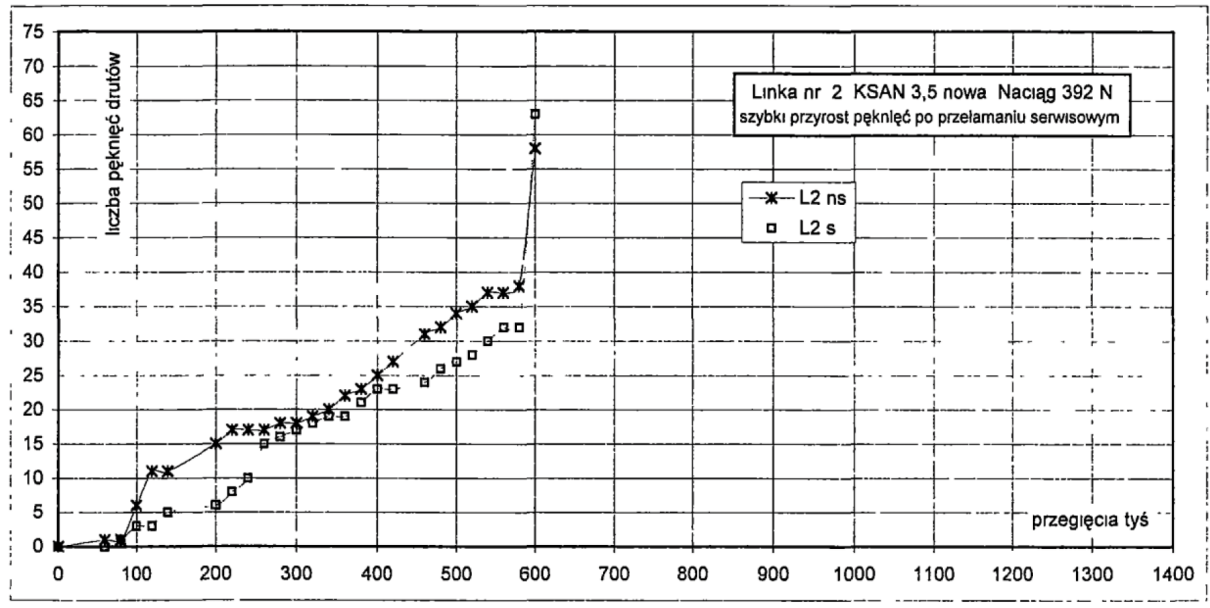

Fig. 6. Test result of the KSAN 3,5 cable specimen number L2 ("Linka nr 2 KSAN 3,5 ...”) endurance test performed for sheaves diameter $64 \mathrm{~mm}$ and tension load $392 \mathrm{~N}$. Number of thousands of reverses is on horizontal axis, while number of broken wires is on vertical axis.

Cable was bent on two sheaves. Test was conducted up to 600000 reverses. Part of the cable ("lower" sheave) was lubricated by grease; number of broken wires for this part is labeled as " $L 2 \mathrm{~s}$ " on the figure, while number for not lubricated part is labeled as " $22 \mathrm{~ns}$ ", 


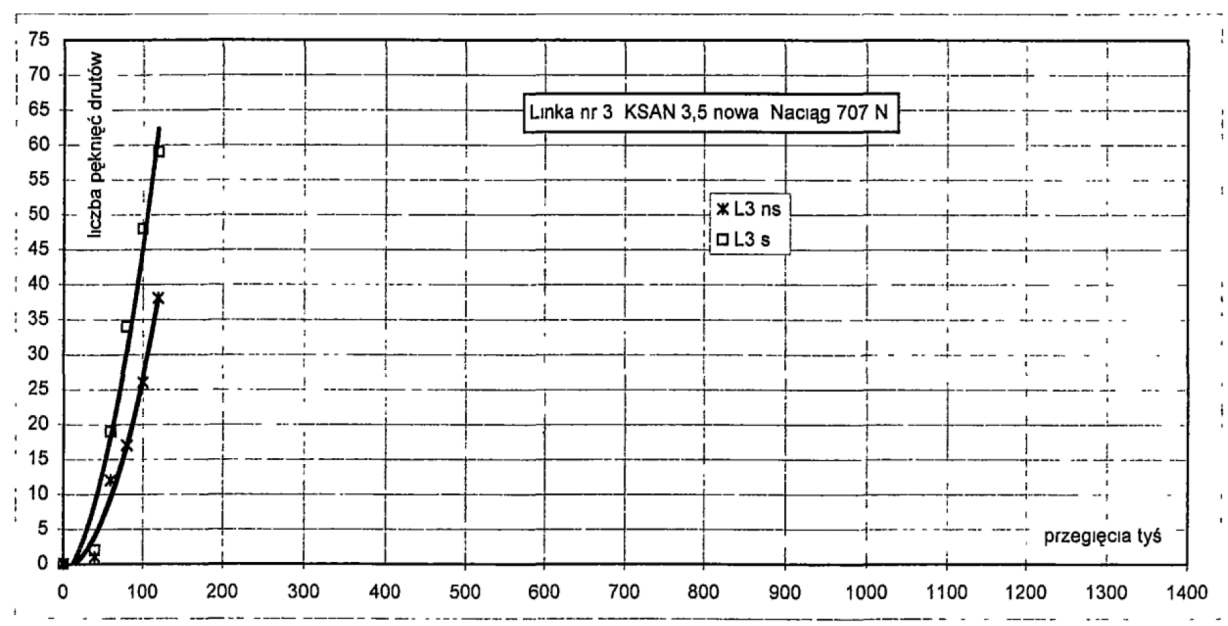

Fig. 7. Test result of the KSAN 3,5 cable specimen number L3 ("Linka nr 3 KSAN 3,5 ...”) endurance test performed for sheaves diameter $64 \mathrm{~mm}$ and tension load $707 \mathrm{~N}$. Number of thousands of reverses is on horizontal axis, while number of broken wires is on vertical axis.

Cable was bent on two sheaves. Test was conducted up to 140000 reverses. Part of the cable ("lower" sheave) was lubricated with grease; the number of broken wires for this part is designated as "L3 s", while the number for the unlubricated part is designated as "L3 ns"

Scatter of test results is shown in Tables no. 2 and $3-$ see below.

\begin{tabular}{|l|c|c|}
\hline Tension load 392 N & \\
\hline Number of test result & $\begin{array}{l}\text { Number of reversals for } \\
\text { 1 wire broken observed }\end{array}$ & $\begin{array}{l}\text { Number of reversals for } \\
27 \text { wires broken observed }\end{array}$ \\
\hline L1ns & 720000 & 420000 \\
\hline L2ns & 60000 & 500000 \\
\hline L5ns1 & 40000 & 300000 \\
\hline L5ns2 & 40000 & 1300000 \\
\hline L6ns & 80000 & 300000 \\
\hline L10ns1 & 40000 & 564000 \\
\hline L10ns2 & 40000 & 375745 \\
\hline mean & 145714 & \\
\hline standard deviation & 234877 & \\
\hline
\end{tabular}

Table 2. Test result of the KSAN 3,5 cable specimens endurance test performed for sheaves diameter $64 \mathrm{~mm}$ and tension load $392 \mathrm{~N}$ as number of reversals for 1 wire broken observed and 27 wires broken observed. For specimens "L1ns" and "L10ns2", number of broken wires during test was lower than 27 


\begin{tabular}{|l|c|c|}
\hline Tension load 707 N & \\
\hline Number of test result & $\begin{array}{l}\text { Number of reversals for } \\
\text { 1 wire broken observed }\end{array}$ & $\begin{array}{l}\text { Number of reversals for } \\
\text { 27 wires broken observed }\end{array}$ \\
\hline L3ns & 40000 & 100000 \\
\hline L4ns1 & 40000 & 80000 \\
\hline L4ns2 & 40000 & 120000 \\
\hline L11ns1 & 60000 & 140000 \\
\hline L11ns2 & 20000 & 110000 \\
\hline mean & 40000 & 22361 \\
\hline standard deviation & 12649 & \\
\hline
\end{tabular}

Table 3. Test result of the KSAN 3,5 cable specimens endurance test performed for sheaves diameter $64 \mathrm{~mm}$ and tension load $707 \mathrm{~N}$ as number of reversals for 1 wire broken observed and 27 wires broken observed. For specimen "L11ns1" number of broken wires during test was lower than 27

Test results showed significant scatter, which was larger for tension load 392 N. Standard deviation of the test results rose with the number of broken wires, but on the other hand the coefficient of variance (ratio of standard deviation and mean value) decreased with the number of broken wires. Of course, limited confidence should be paid for the moment when the first broken wire is observed.

Another observation is that intensity of fatigue damage of wires is significantly influenced by tension load. Although stress analysis does not support this observation, as it indicates a low contribution of tension load to stress level in wires.

\section{NOTES ABOUT INSPECTION OF TENSION IN AIRCRAFT CONTROL CABLES AND AIRCRAFT MAINTENANCE RECOMMENDATIONS}

A significant impact of tension load in the control system cable on the result of the endurance test made the researchers check the real tension load in PZL M28 family cable control systems. Checking the tension with the instruments used by the PZL service resulted in obtaining significantly higher tension values than those given in the aircraft maintenance instruction.

During maintenance inspection, a cable tension meter is in common use - see Fig. 8. Tension meter manufacturers give important notices about the calibration of the instrument and cable tension measurement in aircraft systems [3]. Improper calibration can give false reading of the tension. According to tension meter producer, the simple method that gives a reliable result is a dead weight arrangement. This may be also done in a testing machine against a hydraulic gauge. 
Another issue is that cable tension readings taken on regulated control systems by means of a tension meter could be misleading as the use of the instrument influences tension. Tension measurement has to be adjusted to the particular control system.

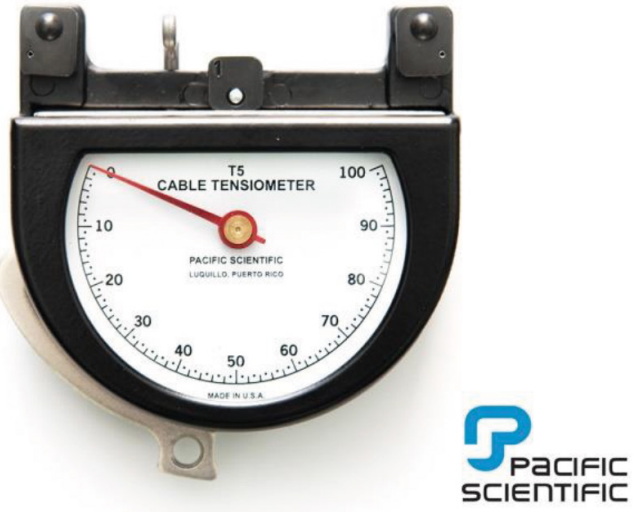

Fig. 8. Pacific Scientific Co. T5 cable tension meter

After the PZL M28 military operator implemented a new method of tension meter calibration, the number of broken wires in the fleet observed during periodic maintenance inspection decreased to the usual level.

\section{CONCLUSIONS}

Steel wire ropes were developed in the $19^{\text {th }}$ century. First stress analyses were performed also at that time. Although issues related to the use of wire ropes in various systems - including cableways, elevators and mining - have been well recognized in more than a century, accidents still occur - including air accidents caused by control system cable damage [4]. This means that one must always follow strict rules for the use of wire ropes, e.g. in aircraft control systems, and analyze their operating conditions on an ongoing basis during the operation of the aircraft.

The influence of the cable tension on the result of durability tests, which is not confirmed in the wires stress analysis, is surprising. It is likely to be caused by the stochastic nature of damage to the wires of the cable during cyclic bending.

\section{BIBLIOGRAPHY}

[1] Russian standard TU 14-4-1266-83 Aviation steel wire ropes "KSAN".

[2] Unpublished reports of PZL Mielec. 
[3] Instructions for Use of Pacific T5 Cable Tensiometer. WI-CU-001 T5 Instructions. Opti Manufacturing Corporation.

[4] Report Accident on 9 August 2007 off the coast of Moorea (French Polynesia) to the DHC6-300 registered F-OIQI operated by Air Moorea. Bureau d'Enquêtes et d'Analyses pour la sécurité de l'aviation civile. 